\title{
Merkez Bankası Para Politikası Stratejileri
}

Doç. Dr. Bülent Doğru

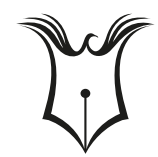




\section{(C) Copyright 2015}

Bu kitabın, basım, yayın ve satış hakları Akademisyen Kitabevi A.Ş.'ne aittir. Anılan kuruluşun izni alınmadan kitabın tümü ya da bölümleri mekanik, elektronik, fotokopi, manyetik kağıt ve/veya başka yöntemlerle çoğaltılamaz, basılamaz, dağıtılamaz. Tablo, şekil ve grafikler izin alınmadan, ticari amaçh kullanılamaz. Bu kitap T.C. Kültür Bakanlı̆̆ bandrolü ile satzlmaktadir.

$\begin{aligned} \text { ISBN } & \text { Yayın Koordinatörü } \\ 978-605-9942-50-8 & \text { Yasin DİLMEN }\end{aligned}$

Kitap Adı Sayfa ve Kapak Tasarımı

Merkez Bankası Para Kerem ACAR

Politikası Stratejileri

Yazar

Yayıncı Sertifika No: 25465

Doç. Dr. Bülent Doğru

Baskı ve Cilt

Sonçağ Matbaacılık ANKARA/2015

\section{DOI}

10.37609/akya.779

\section{GENEL DAĞITIM Akademisyen Kitabevi A.Ş.}

Halk Sokak 5 / A

Yenişehir / Ankara

Tel: o312 4311633

siparis@akademisyen.com

\section{www . a kademisyen . com}




\section{ÖNSÖZ}

Merkez bankalarının ekonomi politikasının önemli bir oyuncusu olması 20 yüzyılın ikinci yarısında mümkün olabilmiştir. Keynezyen iktisat düşüncesini uygulamak için çok sayıda merkez bankası 19501970 arası dönemde kurulmuştur. İki dünya savaşından sonra ard1 ard1na kurulan merkez bankalarının birincil görevleri ekonomik büyümeyi desteklemek ve istihdamı artırmaktı. Para politikaları bu doğrultuda uygulanmıştır. 1970'lerde yaşanan stagflasyonist ortam, merkez bankalarını fiyat istikrarı doğrultusunda para politikası uygulamaya itmiştir. Bu yüzden günümüzde birçok merkez bankası kanununda merkez bankasının temel amacının fiyat istikrarı olduğu açıkça yazılmaktadır. Türkiye Cumhuriyet Merkez Bankası gibi bazı merkez bankalarının temel amacı sadece fiyat istikrarını sağlamak olarak belirlenmiş ve bu ifade merkez bankası kanununa da yazılmıştır. Diğer bütün amaçlar bu temel amaç ile çelişmediği takdirde uygulanabilmektedir. Ancak Amerika merkez bankası federal rezerv gibi bazı merkez bankaları istihdam politikalarını da göz önünde bulundurarak "güvenli, esnek ve istikrarlı bir parasal ve finansal sistem" sağlamayı taahhüt etmektedirler.

1970 yılından sonra merkez bankaları, Milton Friedman'ın “enflasyon her zaman ve her yerde parasal bir fenomendir" sözünden yola çıkarak enflasyon ve para arzı artış hızı arasında doğrudan bir ilişki olduğunu kabul ederek para arzı artış hızını kontrol altında tutarak fiyatlarda istikrar sağlamaya çalışmışlardır. Yani, fiyat istikrarını sağlamak için doğrudan fiyatları hedef almak yerine bir ara rejim (para politikası stratejisi) belirlenmeye çalışılmıştır. Bu rejim doğrultusunda merkez bankası bilançosundaki bir parasal büyüklük hedeflenmiş ve bu büyüklük tutturulmaya çalışılmıştır. Daha sonra para arzı ve enflasyon arasındaki ilişkinin sanıldığı kadar güçlü olmadığı, daha doğrusu enflasyonun sadece para arzından kaynaklanmadığı düşünülmüş ve bu sefer döviz kuru çapası hedeflenerek fiyatlarda istikrar sağlanmaya çalışılmıştır. 1986 yılında Yeni Zelanda merkez bankası, herhangi bir ara hedefe ihtiyaç duymadan fiyat istikrarı için enflasyonun bizzat kendisinin hedeflendiği bir stratejiyi- enflasyon hedeflemesi rejimi- uygulama- 
ya koymuştur. Bu sayede enflasyonu doğrudan kontrol altında tutmayı başarmıştır. Günümüzde Türkiye dâhil çok sayıda merkez bankası Yeni Zelanda'nın başarılı deneyiminden yola çıkarak enflasyon hedeflemesi rejimini uygulamaktadir.

Merkez bankaları fiyat istikrarı temel amacı doğrultusunda para politikası stratejileri belirlemektedirler. İstihdamı arttırıcı ve büyümeyi destekleyici politikalar ikincil amaçlar arasında gelmektedir. Fakat 2008 y1lında yaşanan küresel finans krizinden sonra modern merkez bankacılığı yeni bir evreye geçiş yapmıştır. Buna göre merkez bankaları fiyat istikrarı ve finansal istikrarı birlikte sağlamak gibi oldukça zor bir görevin altına girmişlerdir. Bu yüzden kullandıkları para politikası araçlarında çeşitlilik meydana gelmiştir. Açık piyasa işlemleri, politika faizi, mevduat munzam oranı gibi geleneksel para politikası araçları ile birlikte geleneksel olmayan rezerv opsiyon mekanizması, likidite yönetimi ve faiz koridoru gibi yeni araçlar da artık merkez bankalarınca kullanılmaktadır.

Temel amaç ne olursa olsun merkez bankaları esnek, güvenli ve istikrarlı bir para politikası izleyerek fiyatlarda ve finansal sistemde istikrar sağlamakla görevlidirler. Bu hedefleri tutturmak için ellerinde oldukça çok sayıda araçları vardır. Bu araçların belirlenen strateji doğrultusunda kullanılması ise merkez bankası başkanı ve ekibine kalmıştır.

Son olarak, bu kitap 2012 y1lında İstanbul Üniversitesi Sosyal Bilimler Enstitüsü'nde bitirilen doktora tezimden türetilmiştir. Kitap hakkındaki düşüncelerinizi buldogru@gmail.com adresine gönderebilirsiniz.

Bülent Doğru Mart 2015, Gümüşhane 


\section{İçindekiler}

Önsöz iii

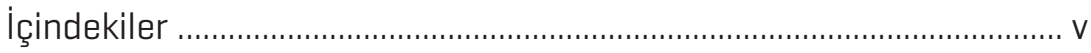

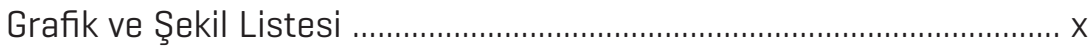

Tablo Listesi ........................................................................................ $\mathrm{xi}$

Teşekkür .........................................................................................

Giriş

Bölüm 1: Merkez Bankacılığı ................................................................ 5

Bir Merkez Bankasına neden ihtiyaç vardır? ........................................ 5

Merkez Bankacılığının Tarihi ................................................................ 6

Merkez Bankalarının Temel İşlevleri ..................................................... 10

Merkez bankalarının Temel Amacı ....................................................... 11

Merkez Bankalarını Görev ve Yetkileri ................................................ 13

Merkez Bankarının Fiyat İstikrarı Görevi .......................................... 14

Kayıp Fonksiyon ......................................................................... 18

Türkiye Merkez Bankası için Kayıp Fonksiyon Hesaplanması ........... 21

Merkez Bankalarının Finansal İstikrar Görevi ..................................... 22

Fiyat İstikrarı ile Finansal İstikrarı Birlikte Sağlanabilir mi? ............ 28

İki Amaç Çok Sayıda Araç .................................................................... 29

Bölüm 2: Türkiye’de Merkez Bankacılığı ................................................. 33

Osmanlı Bankası ............................................................................... 33

TCMB'nin Kurulması ........................................................................... 35

Merkez Bankası Kanun Taslağı ............................................................. 36

TCMB'nin Temel Görevleri ............................................................... 41

TCMB'nin Temel Yetkileri .......................................................................... 42 
$\mathrm{vi}$

Bölüm 3: Merkez Bankası Para Politikası Araçları .............................. 45

Doğrudan Para Politikası Araçları ......................................................... 46

Dolaylı [Geleneksel] Para Politikası Araçları ......................................... 46

Açık Piyasa İşlemleri ............................................................................. 47

Reeskont Politikası ........................................................................ 49

Zorunlu Karşılıklar Politikası .................................................................. 54

Karşılıkların Mevduat Dolanım Hızına göre Ayarlanması Teorisi ...... 58

Friedman'ın Yüzde 100 Karşılık Oranı Önerisi ...................................... 58

Türkiye'de Zorunlu Karşılık Oranlarının Belirlenmesi ve Etkinliği ..... 59

2008 Küresel Finans Krizinden Sonra Türkiye’de

Zorunlu Karşוlıklar .................................................................... 62

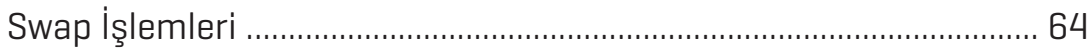

Geleneksel Olmayan Para Politikası Araçları ........................................ 65

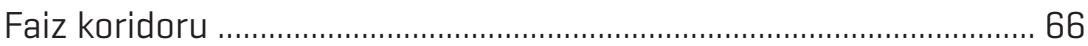

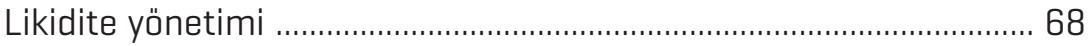

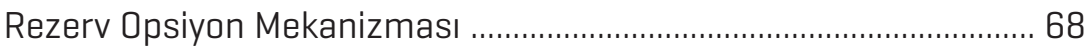

Bölüm 4: Merkez Bankası Bağımsızlığı ve Makroekonomik Değişkenlere Etkisi ............................................................... 71

Merkez Bankalarının Bağımsızlığı ....................................................... 71

Merkez Bankası Bağımsızlığı Zorunluluk mu? ................................... 72

Siyasi ve Ekonomik Bağımsızlık ....................................................... 79

Yasal Bağımsızlık ............................................................................... 79

Araç Bağımsızlığı ........................................................................................ 80

Amaç Bağımsızlığı ............................................................................... 81

Merkez Bankası Bağımsızlığını Ölçme .................................................. 91

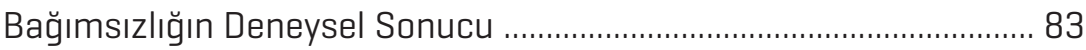

Bölüm 5: Türkiye’de Merkez Bankası Bağımsızlığı İçin Ekonometrik Uygulama .......................................................... 85

Türkiye’de Merkez Bankası Ne Kadar Bağımsız? ................................ 85 
TCMB Bağımsızlığı Büyümeyi Artırmakta mıdır? 88

TCMB Bağımsızlığı Enflasyonu Aşağı Çekmekte midir? ..................... 93

TCM Bağımsızlığı Bütçe Açığını Azaltmakta mıdır? 95

Bölüm 6: Merkez Bankası Para Politikası Rejimleri 99

Merkez bankaları Ara Rejim Hedeflemesine neden ihtiyaç duyarlar? 99

Parasal Büyüklüğe Dayalı Ara Rejim Hedeflemesi .......................... 102

Türkiye’de Parasal Büyüklüğe Dayalı Ara Rejim Hedeflemesi ......... 109

Döviz Kuruna Dayalı parasal Rejim Hedeflemesini ........................... 114

Döviz Krizi Modelleri ................................................................................... 121

Birinci Kuşak Kriz Modelleri ............................................................. 122

İkinci Kuşak Kriz Modelleri ..................................................................... 123

Üçüncü Kuşak Kriz Modelleri ................................................................ 123

Döviz Kuru Çapası Ülke Uygulamaları ................................................ 124

Şili 1978 Tablita İstikrar Programı ................................................. 127

Arjantin'in Tablita İstikrar Programı ................................................... 129

Türkiye Döviz Kuruna Dayalı İstikrar Programı:

Ocak 2000-Şubat 2001 ..................................................... 134

Enflasyon Hedeflemesi Rejimi ............................................................. 135

Nokta Hedefi Ya da Bant Hedefi ............................................................ 141

Zaman Tutarsızlığı ....................................................................... 143

Enflasyon Hedeflemesi Rejiminin Önkoşulları ................................... 144

Fiyat İstikrarı Amacına Sıkı Bağlılık ..................................................... 145

Bağımsız, Hesap Verebilir ve Güvenilir bir Merkez Bankası ............. 145

Sağlam ve Gelişmiş Finansal Piyasalar ........................................... 148

Yüksek Finansal Derinlik ve Düşük Mali Baskınlık ............................ 152

Sağlam Makroekonomik Yapı ve Teknik Altyapı ................................ 158

Enflasyon Hedeflemesi rejiminde Hedef Değişken Seçilmesi ........ 160

Merkez Bankası Hedef Ufku ................................................................. 161 
viii

Türkiye’nin Enflasyon Hedeflemesi Rejimine Geçiş Süreci .............. 163

Türkiye'de Örtük [Implicit] Enflasyon Hedeflemesi Dönemi ........... 165

Türkiye’de Açık [Explicit] Enflasyon Hedeflemesi

Rejimi Dönemi ................................................................ 167

Enflasyon Hedeflemesi Rejiminin Türkiye’de

Uygulama Sonuçları .......................................................... 171

Enflasyon Hedeflemesi Rejiminin Diğer Rejimlerle

Karşılaştırılması ................................................................ 175

Enflasyon Hedeflemesi Rejiminin Avantajları .................................... 175

Enflasyon Hedeflemesi Rejiminin Dezavantajları ............................. 178

Kurala Göre mi Duruma göre mi Politika Uygulanmalı? .................. 180

Enflasyon Hedeflemesi ve Taylor Kural ........................................ 181

Ülke Deneyimleri ve Bazı Uygulamalı Sonuçlar ................................. 183

Yeni Zelanda Deneyimi ........................................................................... 192

İngiltere Deneyimi ................................................................................... 195

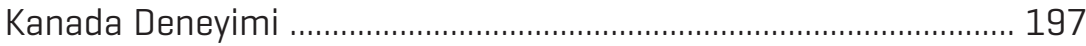

İsrail Deneyimi ....................................................................................... 197

Brezilya Deneyimi ................................................................................. 179

Diğer Parasal Hedefleme Rejimleri .................................................... 200

Nominal GSYiH Hedeflemesi ................................................................ 200

Nominal Faiz Oranları Hedeflemesi ...................................................... 205

Bölüm 7: TCMB Yeni Para Politikası Yaklaşımı

Makro-Ihtiyati Politika ........................................................ 207

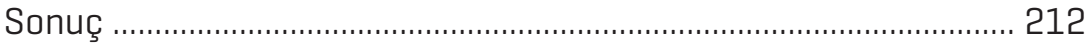

Notlar ve Atıf Yapılan Kaynaklar ....................................................... 215 
varlıklarından güç aldığım Hacer'e ve Bilin'e... 


\section{Grafik ve Şekil Listesi}

Grafik 1. 1 Fiyat istikrarı endeksi . .20

Grafik 1. 2 Enflasyon hedeflemesi rejimi altında merkez bankası kayıp fonksiyon. 21

Grafik 1.3 Çıktı Açığı ve Enflayon Hedefleri .................................................22

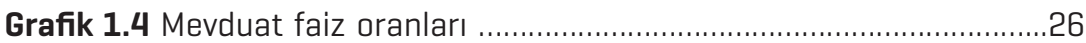

Grafik 1. 5 Döviz kuru ve borsa değişkenliğinden elde edilen endeks ........27

Grafik 1. 6 DiBS Reel Faiz Oranları ve Enflasyon [2003-2011] ...................30

Şekil 1. 2 Türkiye Merkez Bankası Organizasyon Şeması .............................40

Şekil 1.3 Reeskont Oranının Rezervlere Etkisi ............................................51

Grafik 1.6a Reeskont Faiz Oranları ve İşlemlerinde Uygulanan

Faiz Oranları .53

Grafik 1.6b Türkiye’ye Sermaye Girişi [Alt Sol] Ve Türkiye'de Kredi Genişlemesi[Alt Sağ]

Grafik 1.7 Gelişmiş Ülkelerde Merkez Bankası Bağımsızığı ve Ortalama Enflasyon İlişkisi .75

Grafik 1.8 Gelişmiş, Gelişmekte olan ve Az Gelişmiş Ülkelerde Merkez Bankası Bağımsızığı ve Ortalama Enflasyon İlişkisi......78

Grafik 1.9 Türkiye için Büyüme ve Enflasyon İlişkisi: 1923-2010 ..............89

Grafik 1.10 Türkiye'de Çıktı Açı̆̆ı: 1960-2010 Dönemi ...............................90

Şekil 2.4 Para Politikasının Zaman Tutarsızlığı ..........................................144

Şekil 2.6 Enflasyon Aktarım Mekanizması ................................................150

Grafik 2.4 Türkiye'de Finansal Derinlik Oranları ........................................154

Grafik 2.6 Türkiye'de Mali Baskınlık Oranları .......................................157

Grafik 2.8 Döviz Kurundaki Oynaklık [USD Doları, yüzde değişim] ...........159

Grafik 2.9 Başlangıç Koşullarında Kamu Borç Stoğu [Mali Baskınlık] ......166

Grafik 2.10 Güvenirlik Farkı [2002-2005] ...............................................168

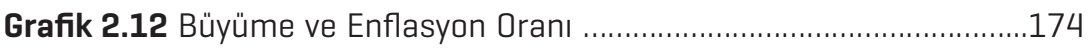

Grafik 2.13 İsrail'e ait Döviz Kuru ve Enflasyon Oranları: 1986-2001 ......198

Grafik 3.25 Türkiye'de Kredi Genişlemesi ...............................................209

Grafik 3.26 Kredi Büyümesi ve Dış Ticaret Dengesi ..................................210

Grafik 3.28 Politika Faizi ve Faiz koridoru ............................................211 


\section{Tablo Listesi}

Tablo 1. 21990 Yılından Önce Kurulan Merkez Bankası Enstitüleri ...............7

Tablo 1.3 Merkez Bankalarının Konvertibilite Durdurmaları ...........................8

Tablo 1.4 Tarihsel Süreçte Dünya daki Merkez Bankası Sayıları ..................... 9

Tablo 1.5 Merkez Bankalarının Mülkiyet Durumuna Göre Sınıflandırılması

Tablo 1.5b. Hazine ve Mevduat Faiz Oranları* ...........................................54

Tablo 1.6 Zorunlu Karşılık Oranları [1980-2011] ........................................61

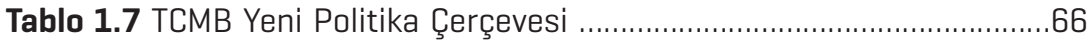

Tablo 1.7a. Gelişmekte Olan Ülkelerde Geleneksel Olmayan Politika Tedbirleri

Tablo 1.8 Merkez Bankası Yasal Bağımsızlık Endeksi ve Yıllık Enflasyon Oranları Arasındaki Ilişki ............................................76

Tablo 1.9 TCMB Yasal Bağımsızlığı [1970-1991] ….................................87

Tablo 1.10 Dönemlere Göre Enflasyon Büyüme Ilişkisi [yüzde] ...................89

Tablo 1.11 Tahmin Sonuçları .....................................................................91

Tablo 1.12 Merkez Bankası Bağımsızlığı ve Bütçe Açığı Arasındaki Illişkiye Üzerine Yapılan Ampirik Çalışmalar................................97

Tablo 1.13 Katsayı Tahminlerinin Sonuçları ...........................................98

Tablo 2 .6 Parasal Büyüklüğe Dayalı Ara Rejim Hedeflemesinde Mali Denge [Bütçe Açığı/GSYiH] ................................................105

Tablo 2.7 Para Stokuna Dayalı İstikrar Programları ..................................108

Tablo 2.8 1986-1989 Dönemi Hedef ve Gerçekleşmeler ............................110

Tablo 2.9 Türkiye'de Uygulanan Parasal Programlar..................................115

Tablo 2.10 Döviz Kuru Krizleri ve Göstergeleri ..........................................122

Tablo 2.11 Döviz Kuruna Dayalı parasal Rejim Hedeflemesini Uygulayan Ülke örnekleri .........................................................126

Tablo 2.12 Şili: Makroekonomik Değişkenler, 1977-1985 ..........................128

Tablo 2.13 Arjantin: Kişi Başı Gelir ve Yıllık Enflasyon Oranlarındaki Değişim 
Tablo 2.14 Arjantin: Makroekonomik Değişkenler, 1979-1987 .................132

Tablo 2.16 Enflasyon Hedefinin Ilan Edilmesi ...........................................138

Tablo 2.18 Enflasyon Hedeflemesi parametreleri ......................................142

Tablo 2.19 Bankacılık Sektörü Sağlamlık Göstergeleri .............................149

Tablo 2.20 Bankacılık ve Ödemeler Bilançosu[parasal]

Krizlerinin Görülme Sıklığı.

Tablo 2.21 1980-1995 Döneminde Gelişmiş ve Gelişmekte Olan

Ülkelerde Makroekonomik Göstergelerdeki

Değişkenlik ve Bankacılık Toplamları

Tablo 2.22 Ülkelerin Enflasyon Hedeflemesine Geçtikleri Yılki Mali Dengeleri [yüzde GSYiH] ............................................... 155

Tablo 2.23 Ülke Gruplarına Göre Mali Baskinlik Oranları [1995] ................156

Tablo 2.26 TÜFE Değişim Oranları ve Enflasyon Hedefleri ..........................170

Tablo 2.27 Hedeflenen Enflasyon ve Gerçekleşen Enflasyon .....................172

Tablo 2.28 TCMB Döviz ve Altın Rezervleri [2002-2011] .........................173

Tablo 2.29 Enflasyon Hedeflemesi, Parasal Hedefleme ve Döviz Kuru Çapası Rejimlerinin Karşılaştırılması .....................176

Tablo 2.30 Seçilmiş Ülkelerin Parasal Büyüme ve Enflayon Oranları ........185

Tablo 2.31 Enflasyon Hedeflemesi Politikasını Uygulayan

Gelişmiş ve Gelişmekte Olan Ülkeler ve Uygulama

Sistematiği [2001 yılına kadar] ...............................................186

Tablo 2.32 Ekonomik Göstergeler - Yeni Zelanda ......................................195

Tablo 2.33 Ingiltere Makroekonomik Ekonomik Göstergeler ....................196

Tablo 2.34 Kanada: Reel Makro Değişkenlerin Volatilitesi, 1981-2000 ....197

Tablo 2.34 Brezilya: Enflasyon Hedeflemesi Öncesi ve

Sonrası Özet Veriler .........................................................................200

Tablo 2.34a En Çok Kullanılan Ara Rejimlere Ait Özet Tablo .....................201 


\section{Teşekkür}

Bu kitap merkez bankalarının fiyat istikrarı hedefi için uyguladıkları para politikası stratejilerine odaklanmıştır. Türkiye Cumhuriyet Merkez Bankası'nın [TCMB] 1986- 2005 arası dönemde uyguladığı parasal büyüklük hedeflemesi stratejisi, 2000-2001 arası dönemde uygulanan döviz kuru çapası, 2002-2005 arası dönemde uygulanan örtük enflasyon hedeflemesi rejimi ve 2005 'ten günümüze kadar uygulanmakta olan açık enflasyon hedeflemesi rejimi detaylı şekilde analiz edilmektedir. Kitapta ayrıca bu stratejileri uygulayan ülke örneklerine de yer verilmektedir.

Bu kitabın altı bölümü İstanbul Üniversitesi Sosyal Bilimler Enstitüsü'nde 2012 yılında bitirilen "Merkez Bankası Politikalarının Fiyat İstikrarı ve Diğer İktisadi Olgular Açısından Değerlendirilmesi ve Türkiye Enflasyon Hedeflemesi Örneği" adlı doktora tezimin bir kısmından türetilmiştir. Dolayısıyla bu kitabın ortaya çıkmasında tez danışmanım Doç. Dr. Dündar Murat DEMIRÖZ’ün büyük emeği vardır. Gerek konu seçiminde gerekse de bana verdiği destek ve değerli katkılar için Dündar Hocam'a çok teşekkür ederim. 


\section{Notlar ve Atıf Yapılan Kaynaklar}

1. Stanley Fischer, "Modern Approaches to Central Banking", NBER Working Paper, No.5064, 1995, s.1-2

2. Modern merkez bankalarının başarısı şu temel varsayımların bir arada uygulanmasıyla daha da artmaktadır: maliye politikasının para politikası ile birlikte belirlenmesi, zaman tutarsızlığı tuzağına düşmemek, para politikasının ileriye dönük olması, hesapverebilirlik yolunun açık olması, para politikasının enflasyona önem verdiği kadar büyümeye ve finansal istikrara da önem vermesi (Frederic Mishkin, "What Should Central Banks Do? " in Monetary Policy Strategy, MIT Prss, 2007, s.37-38).

3. Susanna Kadyrova, "Türk Merkez Bankası Bağımsızlığı ve Makroekonomik Performans Arasındaki İlişki”, (İstanbul Üniversitesi Sosyal Bilimler Enstitüsü Yayınlanmamış Doktora Tezi), İstanbul, 2009, s. 14.

4. Zahide Ayyıldız Onaran, "Para Politikasına Yeni bir Bakış: Merkez Bankası Bağımsızlığı”, (İstanbul Üniversitesi Sosyal Bilimler Enstitüsü Yayınlanmamış Doktora Tezi), İstanbul, 1995, s. 48.

5. Stephen Quinn and William Roberds, "An Economic Explanation of the Early Bank of Amsterdam, Debasement, Bills of Exchange, and the Emergence of the First Central Bank", Federal Reserve Bank of Atlanta FRB of Atlanta Working Paper No. 2006-13, 2006, s.1

6. Ercan Kumcu, "Enflasyon hedeflemesi İtibar Kaybediyor", Habertürk, 23 Mayis 2011.

7. The Riskbank, (Çevrimiçi), http://www.riksbank.com/templates/Page. aspx?id=9159, Erişim:02.02.2011.

8. Bu dönemde hükümetlere daha çok savaş giderlerini karşılamak için borç verilirdi. Bu da ülkede yüksek enflasyon doğmasına yol açmaktaydı. Bu da Danimarkalıların deyimiyle "Statsbankerot (Devletin İflası) demekti bkz., a.e., s. 49

9. Onaran, a.g.e, s. 49.

10. G.J. Santoni, “A private Central Bank; Some Oldes English Lessons”, Federal Reserve Bank of St.Louis Review, 1984, s.66.

11. Konvertibilite, ulusal paraların birbirine kolayca dönüştürülebilmesi anlamina gelir.

12. Onaran, a.g.e., s.52.

13. Ercan Kumcu, "Para Otoritesi ve Para Politikasından Beklenenler", Habertürk Gazetesi, 28 Nisan 2011 
14. Wladyslav Baka, "Please Respect the National Bank", Central Banking, 1994-1995, s.65.

15. Erdinç Tokgöz, "Merkez Bankalarının Bağımsızlığı”, Hacettepe Üniversitesi İktisadi ve İdari Bilimler Fakültesi Dergisi, C.13, 1995, s. 43.

16. Türkiye gibi bazı gelişmiş ve gelişmekte olan ülkeler kanunla merkez bankasının hazineye avans vermesini yasaklayıp merkez bankasına araç bağımsızlığı yanında siyasi bağımsızlık da vermişlerdir.

17. Kadyrova, a.g.e., s. 22.

18. Laars Svensonn, "Inflation Targeting as a Monetary Policy Rule", Journal of Monetary Economics, 1999, s.22

19. E.Castelnumovo, S.Nicoletti-Altimari ve D.Rodriguez-Palenzuela, "Def1nition of Price Stability,Range and Point Inflation Targets: The Anchoring of Long-Term Inflation Expectations", European Central Bank Working Paper, No.273, 2003, s.52.

20. Ezgi Erol, "Enflasyon Hedeflemesi: Türkiye Deneyimi”, (Ege Üniversitesi Sosyal Bilimler Enstitüsü Yayınlanmamış Doktora Tezi), İzmir, 2008, s.16.

21. Bank of Japan, “On Price Stability,”(Çevrimiçi), http://www.boj.or.jp/ en/type/release/zuiji/kako02/data/k001013a.pdf, s.9, Erişim: 24.02.2011.

22. Ercan Kumcu, İstikrar Arayışları, Doğan Kitap, Güncelleştirilmiş 2.Basım, İstanbul, 2002, s.290.

23. A.e., s. 147

24. Milton Friedman, The Role of Monetary Policy, American Ecoomic Review, Vol.58, No.1, pp.1-17, 1968, s.1

25. Christopher J. Niggle," The Endogenous Money Supply Theory: An Institutional Appraisal", Journal of Economic Issues, vol.25, No.1, pp.137-153, 1991 ,s. 140

26. Nadir Eroğlu, İktisatta Rasyonalite ve Para Politikası, Derin Yayınları, İstanbul 2011, s.50-52

27. Jan Tinbergen, On the theory of Economic Policy, Amsterdam, 1952, s.78

28. Eroğlu, a.g.e, s.53-56

29. A.e, s.58-60

30. Kurala göre politikadan sadece Friedman'ın önerdiği sabit parasal büyüme kuralı anlaşılmamalıdır. Kurala göre politika sınırları belirlenmiş bir arala1k içinde hareket etmeyi de kapsamaktadır.

31. A.e, s. 60

32. A.e, s.62 
33. Alan Greenspan, "Opening Remarks: Achieving Price Stability", at a Symposium Sponsored by the Federal Reserve Bank of Kansas City, Jackson Hole, Wyoming, 1996.

34. Bank of Japan, "On Price Stability," (Çevrimiçi), http://www.boj.or.jp/ en/type/release/zuiji/kako02/data/k001013a.pdf, Erişim: 24.02.2011.

35. Süreyya Serdengeçti, "Fiyat İstikrarı," Türkiye Cumhuriyet Merkez Bankası, Başkanın Konuşmaları, SBF Konferansı, Ankara, 28 Kasım 2002.

36. Frederic S. Mishkin ve Klaus Schmidt-Hebbel, "One Decade of Inflation Targeting in The World: What do We Know and What do We Need to Know?" NBER Working Paper, No: 8397, 2001

37. Lars E.O. Svensson, "How Should Monetary Policy Be Conducted in an Era of Price Stability?”, NBER Working Paper, No.7516, s.198.

38. A.Hakan Kara ve Musa Orak, "Enflasyon Hedeflemesi", Ekonomik Tartışmalar Konferans1, Ekim 2008, s.2

39. Durmuş Yılmaz, Para Politikası Sunumu, TCMB, Gaziantep, 7 Haziran 2007, s.3

40. Finn E. Kydland and Edward C. Prescott, "Rules Rather than Discretion: The Inconsistency of Optimal Plans", The Journal of Political Economy, Vol. 85, No. 3, Jun., 1977, pp. 473-492

41. Robert J. Barro ve David B. Gordon," Rules, Discretion and Reputation In A Model of Monetary Policy", NBER Working Paper, No. 1079, February 1983.

42. Suat Oktar, Enflasyon Hedeflemesi, Bilim Teknik Yayınevi,1998, s.36

43. Steve Ambler, "Price Level Targeting and Stabilization Policy: A Review", Bank of Canada Discussion Paper, October 2007, s.5

44. Lars E.O. Svensson, "Price-Level Targeting Versus Inflation Targeting: A Free Lunch?", Journal of Money, Credit, and Banking, Vol.31, ss.277-295, 1999

45. Durmuş Yılmaz, 2011 Ocak Enflasyon Raporu, TCMB, 25 Ocak 2011, Ankara, s.17.

46. TCMB, Y1llik Rapor 2003, s.19

47. GaziErçel, “1998Y11ıPara Politikası Uygulaması:Basın Toplantısı”,Türkiye Cumhuriyet Merkez Bankasi, Ankara, 8 Ocak 1998.

48. Erdem Başçı, "Para Politikaları ve finansal İstikrar", Ekonomi Yaz Seminerleri 2011 Pamukkale Üniversitesi, Denizli, 22 Temmuz 2011

49. TCMB, Finansal İstikrar Raporu I, 2006, s.8

50. TCMB, Finansal İstikrar Raporu, Aralık 2010, s.5. 
51. Fatih Özatay, “BDDK ile Merkez Bankası Birleşsin mi?”, Radikal Gazetesi, 12 Eylül 2011

52. Merkez bankası Faiz koridoru olarak gecelik borç verme ve borçlanma faizleri arasındaki farkı genişleterek faiz koridorunu aktif bir para politikası aracı haline getirip, faizlerdeki oynaklığını minimize etmeye ve esnek bir faiz politikası izlemeye çalışmaktadır (Başçı, a.g.e, s.5)

53. TCMB, Finansal İstikrar Raporu, Mayıs 2011, s.22-23

54. Kumcu, 9 Ayda Etki Yapmayan Politika Politika Olamaz

55. Durmuş Yılmaz, 2011 Ocak Enflasyon Raporu Basın Toplantıs1, 25 Ocak 2011, Ankara, s.3-4

56. TCMB, Sıkça Sorulan Sorular, (Çevrimiçi), http://www.tcmb.gov.tr/yeni/ iletisimgm/sss.php, Erişim: 04.10.2011

57. TCMB, 2011 Yılında Para ve Kur Politikaları, 21 Aralık 2010, Ankara, S.4

58. Gazı Erçel, "Türkıye'de Para Polıtıkası Uygulamaları ve Etkılerı", Ankara Ünıversıtesı Sıyasal Bılgıler Fakültesı, Ankara, 14 Kasım 1996, (Çevrimiçi): http://www.fiyatlari.org/news/Turkiyede-Para-Politikasi-uygulamalarive-Etkileri-n1.html, Erişim: 21.04.2011

59. Tam Türkçe karşılığı olmayan bu kelimenin "makro öngörü” olarak çevrilmesi doğru olacaktır.

60. TCMB finansal istikrar raporu, Kasım-Aralık 2014, s.38

61. TCMB finansal istikrar raporu, Kasım-Aralık 2014, s.48

62. TCMB, Finansal İstikrar Raporu, Kasım 2009, s.6.

63. TCMB, Finansal İstikrar Raporu, Mayıs 2010, s.5.

64. Küresel krizden önce finansal istikrara önem verilmiyor değildi. Örneğin Nisan 2001 yılında değişen TCMB yasasının 4.madesinde bankanın temel görevleri arasında finansal istikrarı sağlayıcı tedbirleri almak" ifadesi kullanılmıştır. Ayrıca 1990'lar boyunca koyduğu parasal programlarında zaman zaman finansal istikrarı fiyat istikrarının önüne aldığı da olmuştur. Fakat bizim bildiğimiz TCMB'nin ve diğer dünya merkez bankalarının küresel krizden önce finansal istikrara fiyat istikrarı kadar önem vermedikleridir.

65. TCMB, Sıkça Sorulan Sorular, (Çevrimiçi), http://www.tcmb.gov.tr/yeni/ iletisimgm/sss.php, Erişim: 04.10.2011

66. Taylor kuralı (Taylor rule) şu denklemle ifade edilir: $i=(1+\delta) \pi+\beta y+r-\delta^{*}, \delta$ ve $\beta>0, y=\left(Y-Y_{N}\right) / Y$ burada i, srrayla nominal faizler, enflasyon ve üretimi, ise reel faiz oranlarını göstermektedir.

67. TCMB, Finansal İstikrar Raporu, Aralık 2010, s.50

68. A.e., 
69. Erdem Başç1, “The Turkish Experince”, Bank of Indonesia and IMF Joint Conference on Coping with Asia's LArge Capital Inflows in a Multi-Speed Global Economy, Bali, Indonesia, March 11 2011, s.12.

70. A.e., s.19.

71. Fatih Özatay, "Nasıl Oluyor da Oluyor? Para Politikası (4)”, Dünya Gazetesi, 23 Mayıs 2011

72. Faiz Koridoru genişliği=MB gecelik borç alma ve borç verme faiz oranları arasınki fark

73. Bu kısım genel olarak TCMB web sitesindeki 'tarihçe' kısmından alıntılanmıştır, (Çevrimiçi), http://www.tcmb.gov.tr/, Erişim: 03.02.2011

74. Gülten Kazgan, Tanzimat'tan 21.Yüzyıla Tükiye Ekonomisi, Bilgi Üniversitesi Yayınları, 4. Bask1, İstanbul, 2009, s.48

75. 1715 Sayılı Merkez Bankası Kanununun Özellikleri:

- 11 Haziran 1930 tarih, 1715 sayılı Cumhuriyet Merkez Bankası Kanunu uyarınca, Merkez Bankası 15 milyon Türk Lirası sermayeli bir anonim şirket olacak, banknot ihraç etme yetkisini 30 yıllık bir süre için kullanacaktı. Bu süre, bitimine beş yıl kala uzatılabilecekti.

- Merkez Bankasının temel amacı ülkenin ekonomik kalkınmasını desteklemekti. $\mathrm{Bu}$ amaçla reeskont oranlarını belirleyecek; para piyasasını ve paranın dolaşımını düzenleyecek; Hazine işlemlerini yerine getirecek; Türk parasının değerini korumak için hükümetle ortaklaşa tüm önlemleri alacakt1.

- Banka'nın hisse senetleri dört gruba ayrılmıştır. A sınıfı hisse senetleri Hükümet kuruluşlarına ait olup, toplam sermayenin yüzde 15 'ini geçemeyecektir. B sınıfı hisse senetleri milli bankalara ayrılmıştır. Banka sermayesinin yüzde 10 'unu teşkil eden 15000 adet $C$ sınıfı hisse yabancı bankalar ile imtiyazlı şirketlere tahsis edilmiştir. D sınıfı hisse senetleri ise Türk ticaret kuruluşlarıyla Türk uyruklu gerçek ve tüzel kişilere ayrılmıştır.

- Her anonim şirkette olduğu gibi, temel bir organ olarak Hissedarlar Umumi Heyeti vardır. Banka'nın en yüksek yönetim organı 8 kişilik İdare Meclisi'dir. İdare Meclisi "Banka üzerinde tam selahiyet ve murakabe hakkını haizdir. Banka'yı alakadar eden bütün işlerle iştigal” edecektir. Banka 4 kişilik bir Murakabe Komisyonu'nca denetlenecektir. Banka'nın en güçlü kişisi İdare Meclisi Reisi'dir. Banka'nın iskonto, reeskont ve faiz hadlerini ve kredi işlerini düzenleyecek bir İskonto ve Kredi Encümeni vardır. Banka'nın beşinci organı İdare Heyeti'dir. İda- 
re Heyeti Umum Müdür'ün başkanlığında Umum Müdür Muavini ve Muhasebe Müdürü'nden oluşmaktadır. Umum Müdür, İdare Meclis'nin teklifi ve Bakanlar Kurulu kararıyla Cumhurbaşkanı tarafından beş yıl süre ile tayin edilir

76. Kepenek ve Yentürk, a.g.e.

77. Erçel, Bulgaristan Merkez Bankası'nın 120. Kuruluş Yıldönümü Münasebetiyle Yapılan Konuşma, 1999.

78. Rüşdü Saraçoğlu, “Türkiye'de Merkez Bankacılığı”, İşletme ve Finans Dergisi, Ağustos 1993, s.20.

79. Fatma Doğruel ve A. Suut Doğruel, Türkiye'de Enflasyonun Tarihi, TCMB ve Tarih Vakfi Ortak Yayını, İstanbul, 2005.

80. John Williamson ve Molly Mahar, Finansai Liberizasyon Üzerine Bir İnceleme, Çev.: Güven Delice, Liberte Yayınları, 2002, s.42

81. Rıdvan Karluk, Türkiye Ekonomisi Tarihsel Gelişim Yapısal ve Sosyal Değişim, Beta Basım, Yayım Dağıtım A.Ş., İstanbul, 1996, s. 31

82. Yakup Kepenek ve Nurhan Yentürk, Türkiye Ekonomisi, 22. Basım, Remzi Kitabevi, İstanbul, 2009, s.233.

83. Erçel, Bulgaristan Merkez Bankası'nın 120. Kuruluş Yıldönümü Münasebetiyle Yapılan Konuşma, 1999.

84. Fatih Özatay, Nasıl Oluyor da Oluyor Finansal Krizler-1, Dünya Gazetesi, 3 Ağustos 2011

85. TCMB, (Çevrimiçi), www.tcmb.gov.tr, Erişim: 02.01.2011.

86. TCMB, Bülten, Mart 2006, s.3.

87. A.e.,

88. Madde 40- I- a) (25.4.2001 tarih, 4651 sayılı Kanun ile değiştirilen şekli) Banka, nihai kredi mercii sıfatıla ödeme sisteminde aksamalara sebep olabilecek geçici likidite sıkışıklıklarını ve finansal piyasaların etkin bir şekilde çalışmasını engelleyebilecek teknik kaynaklı ödeme sorunlarını gidermek amacıyla, sisteme, teminat karşılığında gün içi veya gün sonu kredi imkanı sağlayabilir.

89. Merkez Bankası bütün hazine işlemlerini memleket içi ve dışı her nevi para nakil ve havale işlerini ücretsiz yapar.

90. Risk Merkezinin bütün işlem ve kayıtları gizlidir.

91. Y1lmaz, a.g.e., s.19

92. Dilara Ertuğ, “ Türkiye İçin Faiz Oranı Reaksiyon Fonksiyonu ve Taylor Kuralı: Eşbütünleşme Yaklaşımı”, (Gazi Üniversitesi Sosyal Bilimler Enstitüsü Yayınlanmamış Doktora Tezi), Ankara, 2007, S.6. 
93. Esnek hareket etmek burada büyük ölçekli alımlarla küçük ölçekli alımları yapabilecek kadar geniş bir marjda hareket serbestîsine sahip olmak anlamında kullanılmıştır.

94. A.e., s.7

95. Merih Paya, Para Teorisi ve Para Politikası, Filiz Kitabevi, 2.Bask1, İstanbul-1998, s.167.

96. A.e.

97. Vesika, paraya dönüştürülebilen belgedir.

98. Reeskont, bir bedel karş1lığı iskonto edilmiş, el değiştirmiş olan kıymetlerin yeniden bir bedel karşıllı̆ı el değiştirmesini ifade eder (TCMB).

99. TCMB, Sıkça Sorulan Sorular, (Çevrimiçi), tcmb.gov.tr, Erişim: 12.04.2010 100. Zafer Tunca, Makro İktisat, Filiz Yayınevi, 4.Bask1, İstanbul, 2005, s.188.

101. Susanna Kadyrova, "Türk Merkez Bankası Bağımsızlığı Ve Makroekonomik Performans Arasındaki İlişki”, (İstanbul Üniversitesi Sosyal Bilimler Enstitüsü Yayınlanmamış Doktora Tezi), İstanbul, 2009, .s.172

102. Süleyman Yaşar, "Dalgalı Kur Doğru Tercih", Radikal Gazetesi, 08.08.2011

103. Yilmaz, a.g.e, s.7

104. Simon Gray, "Central Bank Balances and Reserve Requirements." IMF Working Paper, No. 11/36, 2011, s.7.

105. Koray Alper, S.Tolga Tiryaki, "Zorunlu karşıllkların Para politikasındaki Yeri”, TCMB Ekonomi Notlar1, sayı 2011-08/13 Nisan 2011, 2011, s.8

106. A.e., s.8-9

107. Para çarpanı=para arzi/parasal taban.

108. İlker Parasız, Para Politikası, 6.baskı, Ezgi Kitabevi, 2003, s.17.

109. A.e., s.18.

110. MV=PY denkleminde sağ taraf harcamalar yoluyla GSYİH vermektedir. $\mathrm{Bu}$ da para miktarı ile dolanım hızının çarpımına eşittir.

111. İlker Parasız, İktisada Giriş, 8. Baskı, Ezgi Kitabevi, Bursa, 2006, s.498-499.

112. Erdem Başçı ve Hakan Kara, "Finansal İstikrar ve Para Politikası", TCMB Çalışma Tebliğleri, No.11/08, 2011, s.6

113. A.e., s. 20

114. Bu tez çalışması devam ederken zorunlu karşılıklar 6 ay içinde üç kez değiştirildi

115. Paya,a.g.e., ,s.171.

116. Ercan Kumcu, "Ekonomi Politikalarının Zaman İhtiyacı", Habertürk, 17 Nisan 2011. 
117. Başçı ve Kara, A.g.e, s.17

118. TCMB, Zorunlu Karşılıklara İlişkin Basın Duyurusu, 5 Ekim 2011, (Çerimiçi) http://www.tcmb.gov.tr/, Erişim: 11.10.2011

119. Vural, U. (2013), “Geleneksel Olmayan Para Politikalarının Yükselişi “, Tcmb Uzmanlık Yeterlilik Tezi, Ankara.

120. A.e., s.172.

121. Döpor, yabancı paranın vadeli kuru spot piyasa kuruna göre düşük ise yabancı para birimi için döpor vardır denir.

122. Röpor: yabancı paranın vadeli kuru spot piyasa kuruna göre primli ise yabancı para için röpor vardır denir

123. Vural, 2013, s.61-63

124. Ömer Eroğlu ve Halil Altıntaş, "Merkez Bankasının Bağımsızlığı Sorunu: Enflasyon ve Ekonomik Performans Üzerine Bir Değerlendirme", İktisat İşletme ve Finans Dergisi, C:12, S.135, Haziran 1997, s.50.

125. Melike Alparslan ve Pelin Ataman Erdönmez, "Enflasyon Hedeflemesi”, Bankacılar Dergisi, Sayı.35, Aralık 2000, s.14.

126. Carl E. Walsh, "Central Bank Independence Prepared for the New Palgrave Dictionary", December 2005, s.1, (Çevrimiçi), http://people.ucsc. edu/ walshc/MyPapers/cbi_newpalgrave.pdf, Erişim: 03.12.2011

127. Ekrem Gül, Aykut Ekinci ve Arif A. Gürbüz, Enflasyonla Mücadelede Enflasyon Hedeflemesi, Ekin Yayınları, Bursa, 2006, s.78.

128. Alex Cukierman, Central Bank Strategy, Credibility, and Independence: Theory and Evidence, Cambridge: The MIT Press, 1994

129. A.e.

130. J.S.Mill ve A. Marshall çıkarcı birey yaklaşımını kabul etmemişlerdir.

131. Eroğlu, İktisatta Rasyonalite ve Para Politikası, s.34-38

132. Daniel Kahneman ve Amos Tversky, "Prospect Theory: An analysiz of Decision Under Risk", Econometrica, vol.47, no.2,pp. 263-291, 1979, s. 263

133. Tian Huang, "Effects of Central Bank Independence Reforms on Inflation in Different Parts of the World", Högskolan Dalarna, 2011,s.2

134. Daha fazla bilgi için bkz. Vittorio Grilli, Donato Masciandaro and Guido Tabellini, "Political and Monetary Institutions and Public Financial Policies in the Industrial Countries", Economic Policy, 1991, s. 342-392.; Sylvester C.W. Eijfinger, and Eric Schaling, "Central Bank Independence : Criteria and Indices", Reserarch Memorandum No 548, Department of Economics, Tilburg University, 1992.; Guy Debelle, Stanley 
Fischer, "How Independent Should a Central Bank Be?", Working Papers in Applied Economic Theory, 94-05, Federal Reserve Bank of San Francisco, 1994.; Robin Bade \& Michael Parkin, "Central Bank Laws and Monetary Policy",University of Western Ontario, October 1988.; Alex Cukierman, Steven B. Webb and Bilin Neyapti, "Measuring the Independence of Central Banks and It's Effect on Policy Outcomes", The World Bank Economic Review, Vol: 6, No: 3, September, 1992, s.52'den aktaran Murat Kaykusuz, "Merkez Bankasının Bağımsızlığı ve Enflasyon Arasındaki İlişki" , (Çevrimiçi), http://kaykusuz.tripod.com/id44.html., Erişim: 23.04.2011

135. David Romer, Advanced Macroeconomics, Third Edition, The McGrawHill, 2006, s. 518

136. David Romer, Advanced Macroeconomics, Third Edition, The McGrawHill, 2006, s. 518.

137. V. D. Masciandaro Grillı ve G. Tabellini, "Political and Monetary Institution and Public Financial Policies in Industrial Countries", Economic Policy, Vol. 6, No. 13, Oct. 1991, s.198-210.

138. Suat Oktar, Merkez Bankasının Bağımsızlığı, Birinci Baskı, İstanbul: Bilim Teknik Yayınları, Ekim 1996, s.84

139. Süreyya Serdengeçti, "I- Merkez Bankası Bağımsızlığı”, Finansal Politik Ekonomik Yorumlar Dergisi, Y11:3, S:477, Aralık 2003, s.46.

140. Oktar, Merkez Bankasının Bağımsızlığı,.84-85'den Aktaran: İlhan Eroğlu, "Enflasyon .Hedeflemesi Rejimi ve Türkiye Uygulamasının Performans Analizi”, , (Marmara üniversitesi Sosyal Bilimler Enstitüsü Basılmamış doktora tezi) İstanbul 2009, s.92

141. Salih Barışık, "Merkez Bankası Bağımsızlığı, Makroekonomik Etkileri ve 2001 Tarihli TCMB Kanununun Yansımaları", Ankara Üniversitesi SBF Dergisi, Cilt.59, Sayı.3, 2004, s.3.

142. Fatih Özatay, Parasal İktisat Kuram ve Politika, Efil Yayınevi, Ankara, 2011, s.315.

143. Alberto Alesina and Lawrence. H. Summers, "Macroeconomic Performance: Some Comparative Evidence", Journal of Money, Credit and Banking, Vol.25, No. 2, 1993, pp. 151-163, s. 151-153.

144. Bayram Çolakoğlu, "Enflasyon Hedeflemesi Stratejisine Geçiş Bağlamında TC Merkez Bankası Bağımsızlığının Fonksiyonelliği”, Kocaeli Üniversitesi Sosyal Bilimler Enstitüsü Dergisi, 2002/2: 1731, s.19. 
145. Almila Karasoy, Mesut Saygılı, Cihan Yalçın, "Enflasyonun Doğrudan Hedeflenmesi Politikası ve Bazı Ülke Deneyimleri”, TCMB Araştırma Genel Müdürlüğü Tartışma Tebliği, Ankara, No. 9801, Mart 1998, s.31.

146. Eroğlu, a.g.e., s.92

147. Süreyya Serdengeçti, "Merkez Bankası Bağımsızlı̆̆ı”, Şubat 2005, s. 6, (Çevrimiçi), http:// www.tcmb.gov.tr, Erişim: 12.06.2011

148. Sylvia Maxfield, Gatekeepers of Growth: The International Political Economy of Central Banking in Developing Countries, Princeton University Press, 1997, s.9-10

149. Robin Bade ve Michael Parkin, "Central Bank Laws and Monetary Policy", Basılmamış Çalışma

150. Vittorio Grilli, Donato Masciandaro ve Guido Tabellini, "Political and Monetary Institutions and Public Financial Policies in the Industrial Countries", Economic Policy, 1991, pp. 342-392.

151. Alex Cukierman, Steven B. Webb and Bilin Neyapti, "Measuring the Independence of Central Banks and It's Effect on Policy Outcomes", The World Bank Economic Review, Vol: 6, No: 3, September, 1992. pp.353398, s.358-360.

152. 1992 yılına ait bir çalışma olduğuna vurgu yapalım

153. Cukierman, Webb ve Neyapti, a.g.e., s.374.

154. Cukierman, Webb ve Neyapti, a.g.e., s.374.

155. Hasan Can Oktaylar, KPSS A İiktisat, Yarg1 Yayınları, 2010, s.468.

156. TCMB, (Çevrimiçi), http://www.tcmb.gov.tr/, Erişim: 10.03.2011.

157. TCMB,

158. Türkiye Cumhuriyet Merkez Bankası Kanunu, Kanun No: 1211, Kabul Tarihi: 14.1.1970, (çevrimiçi), http://tcmb.gov.tr/, Erişim: 12.12.2010

159. Enflasyon hedefini hükümetle ortaklaşa belirler anlamına gelmektedir.

160. Durmuş Yılmaz, Para Politikası Sunumu, TCMB, Gaziantep, 7 Haziran 2007, s.5.

161. Bülent Günsoy, "Hukuksal Yap1 ve İktisadi Başar1 : TCMB Örneği”, İ.Ü.Siyasal Bilgiler Fakültesi Dergisi No: 23-24, Ekim 2000-Mart 2001,(Çevrimiçi), http://www.istanbul.edu.tr/siyasal/dergi/sayi23-24/13. htm., Erişim: 23.04.2011

162. Nuran Gökbudak, "Central Bank Independence, The Bundesbank Experience and the Central Bank of the Republic of Turkey" Discussion Paper, No. 9610, 1996. 
163. Zekâyı Kaya, "Türkıye Cumhurıyet Merkez Bankasının Bagımsızlıgı ve Enflasyon Ilıskısi”, (Marmara Üniversitesi Sosyal Bilimler Enstitüsü Iktısat Anabılım Dalı Iktısat Polıtıkası Bııım Dalı Yayınlanmamış Doktora Tezi) Istanbul, 2007

164. Gazi Erçel, Açılış konuşması, 1996, s.97

165. Taylor benzeri kurallar merkez bankasının kısa vadeli faiz oranları ile üretimi kontrol edebileceği ve reel üretimden sapma ile mevcut enflasyonun hedeflenen enflasyondan apmasının bir fonksiyonu olarak modelleyebileceğini ortaya koymaktadır.Taylor kuralı özellikle gelişmekte olan ülkelerde finansal zayıflık ve enflasyon değerinden sapma neticesinde ortaya çıkan istikrarsızlıklardan ötürü bu ülkelerde iç dinamiklere uygulanmasını gerektirmektedir (Eroğlu, Rasyonalite, s.74)

166. John B. Taylor, "Discretion Versus Policy Rules in Practice" CarnegieRochester Conference Series on Public Policy, No.39, 1993, pp.195-214, s.202

167. Nadir Eroğlu, Anar Abdullaev, “CWN Bağımsızlık Ölçütlerinin TCMB'ye Uygulanması”, Doğuş Üniversitesi Dergisi, 6 (1) 2005, ss.79-97,s.81-96

168. Robert Barro, "Inflation and Economic Growth", NBER Working Paper, No.5326, October 1995, s.1

169. Bora Süslü ve Selahattin Bekmez,’Türkiye'de Zaman tutarsızlığının ARDL Yöntemi ile incelenmesi”, BDDK Bankacılık ve Finansal Piyasalar, Cilt:4, Say1:2, 2010, ss 85-110, s.124

170. Alesina ve Summers, a.g.e., s.159.

171. Özatay, Parasal İktisat Kuram ve Politika, s.317

172. Cukierman, Webb ve Neyapt1, a.g.e., s. 370 .

173. Ekonometrik modellemeden önce değişkenlerin durağanlık düzeyleri Augmented Dickey-Fuller (ADF) birim kök testi ile sınanmıştır. Sınama sonucu değişkenlerin birinci mertebeden durağan oldukları ortaya çıkmıştır. Aynı mertebeden olma durumu yalancı regresyon ihtimalini yok edip, uzun dönemli ilişkileri yakalama şansı verdiğinden, fark almadan denklem tahmininde bulunmak mümkündür.

174. Bade ve Parkin, a.g.e., s. 23

175. Cukierman, Webb ve Neyapt1, a.g.e., s.374

176. Maxwell J. Fry, “Assessing Central Bank Independence: Do Actions Speak Louder than Words?" Oxford Economic Papers, No.50, ss.512-529, s.513 
177. Maxwell J. Fry, Emancipating the Banking System and Developing Markets for Government Debt, Routledge Publisher, London, 1997, s.4

178. Ayrıntılı analiz için bkz. Haan, J. de and Zelhorst, D. "The İmpact Government Deficits on Money Growth in Developing Countries", Journal of International Money and Finance, No. 9, pp.455-69,1990.

179. Bernd Jan Sikken ve Jakob De Haan, "Budget Deficits, Monetization, and Centralbank İndependence In Developing Countries “, Oxford Economic Papers, No. 50, pp.493-511, 1998, s.494.

180. Haziran 2011 seçimleri öncesi Türkiye'de reel faizlerin sıfır olması için Başbakan'ın ortaya koyduğu tavır politik baskıdır. Ancak unutulmamal1dır ki uzun vadede reel faizler asla sıfir olamaz. Reel faiz aslında tasarruf sahiplerinin belirsizlik ortamında biriktirdikleri varlıkları için istedikleri risk primi, yani sigortadır. Uzun vadede tasarruf sahipleri sıfir reel faizi ödül olarak görmeyecekleri için tasarruf etmekten kaçınacaklardır. Bu yüzden de sıfir reel faiz olmaz. Ancak kısa vadede reel faizler sıfir olabilir.

181. Üstü noktalı $\mathrm{B}^{*}$ ve $\mathrm{M}^{*}$ ifadeleri bu değişkenlerin zamana göre türevini göstermektedir.

182. Sikken ve Haan, a.g.e., s.494-495.

183. Ayrıntılı bilgi için bkz. Haan, J. de and Sturm, J.E. (1992). "The Case for Central Bank Independence", Banca Nazionale del Lavoro Quarterly Review, No. 182, pp.305-27 ; Fry, M. (1998). 'Assessing Central Bank Independence: Do Actions Speak Louder than Words?', Oxford Economic Papers, 50, 512-2; Cukierman, A. (1992). Central Bank Strategy, Credibility, and Independence, MIT Press,Cambridge; Grilli, V., Masdandaro, D., and Tabellini, G. (1991). 'Political and Monetary Institutions and Public Financial Policies in the Industrial Countries', Economic Policy, 13, 341-392; Masciandaro, D. and Tabellini, G. (1988). 'Fiscal Deficits and Monetary Institutions: a Comparative Analysis', in H. Cheng (ed.), Challenges to Monetary Policy in the Pacific Basin Countries, Kluwer Academic Publishers, Dordrecht

184. Bkz. Protopapadakis, A.A., and Siegel, J.J. (Money Growth and Inflation Related to Government Deficits? Evidence from Ten Industrialized Economies', Journal of International Money and Finance, 1987, ss. 31-48.; Haan, J. de and Zelhorst, D. (1990). "The impact government deficits on money growth in developing countries', Journal of International Money and Finance, 9, 455-69. 
185. Merkez bankası yasal bağımsızlığı için Bernd Jan Sikken ve Jakob De Haan, "Budget Deficits, Monetization, and Centralbank İndependence In Developing Countries “, Oxford Economic Papers, No. 50, pp.493-511, 1998, s.511 ve Hakan Berument ve Bilin Neyapt1, "Türkiye Cumhuriyet Merkez Bankası Ne Kadar Bağımsız?", Yayınlanmamış Çalışma, 2000, s.9-10 referans alınmıştır.

186. Frederic S. Mishkin, "Internatıonal Experiences With Different Monetary Polıcy Regimes”, Seminar Paper, No. 648, 1998, s.1-2.

187. Jeffrey Sachs, Aaron Tornell and Andres Velasco, "Financial Crises in Emerging Markets: The Lessons From 1995”, NBER Working Paper, No. 5576, 1996, s.22

188. A.e.

189. Kiguel ve Liviatan, a.g.e., s.6

190. Stanley Fischer, "Maintaining Price Stability”, Finance and Development, December 1996, s.34-37, s.36

191. Erçel, Türkıye'de Para Polıtıkası Uygulamaları ve Etkılerı, 1996.

192. Kara ve Orak, a.g.e., s.2.

193. Calvo ve Vegh, a.g.e.,, s. 22.

194. Kemal Yıldırım ve Mustafa Özer, İktisat Teorisi, Anadolu Üniversitesi Yayınları, 4.baskı , Ekişehir, 2006, s.413

195. Eric Helleiner "Historicizing Territorial Currencies: Monetary Space And The Nation-State İn North America”, Political Geograph, No.1, 309-339, t.y, s.309

196. Nadir Eroğlu, "The Effects of Financial Globalization on Economic Policies", International Research Journal of Finance and Economics, ISSN 1450-2887 Issue 47 (2010),pp.90-95, s.92

197. DPT, Sekizinci Beş yıllık Kalkınma Planı küreselleşme Özel İhtisas Komisyonu Raporu, Ankara, 2000, s.55

198. Vito Tanzi, "Globalization and the Work of Fiscal Termites", A Quarterly Magazine of The IMF, , March 2001

199. Joshua Aizenman, "The İmpossible Trinity (Aka The Policy Trilemma)", The Encyclopedia of Financial Globalisation, May 2010, s.1-6.

200. Tablo 2.6' da bu durum görülmektedir.

201. Oktar, Enflasyon Hedeflemesi, s.19

202. Oktar, Enflasyon Hedeflemesi, s.20

203. 1975 yılından beri İsveçre M1 parasal büyüklüğü üzerinden ara stratejiler belirlemektedir. 
204. Otmar Issing, "The European Central Bank at the Eve of EMU", Speech in London, November 26, 1998.

205. Ben Bernanke and Frederic S Mishkin: "Inflation Targeting: A New Framework for Monetary Policy?”, NBER Working Papers, No.5893, January 1997, s.8

206. Oktar, Enflasyon Hedeflemesi, s.22

207. Aaron Tornell and Andres Velasco, "Fiscal discipline and the choice of a nominal anchor in Stabilization", Journal of International Economics, No.46, 1997, s.21-22

208. Ünal Çağlar, Döviz Kurları Uluslararası Para Sistemi ve Ekonomik İstikrar, Alfa Yayınları, 2003, s.156

209. Bireylerin nominal sabit paraya rağmen reel ankes taleplerini arttırması hasılada düşme ile neticelenecektir

210. Çağlar, a.g.e.

211. Svensson, Inflation Targeting as a Monetary Policy Rule, .23

212. Friedman, Studies in the Quantity Theory of Money, University of Chicago Press, 1956, s.4

213. Eroğlu, İktisatta Rasyonalite ve Para Politikası, s,50

214. John Maynard Keynes, Genel Teori, İstihdam, Faiz ve Paranın Genel Teorisi, Çev. Uğur Selçuk Akalın Kalkedon Yayınları, , İstanbul, 2008.

215. Parasız, Para Politikas1, s.101-102

216. Kiguel ve Liviatan, a.g.e., s.35-36

217. Oktar, Enflasyon Hedeflemesi, s.7

218. Fatih Özatay, "Nasıl Oluyor da Oluyor? Para Politikası (2)", Dünya Gazetesi, 4 Mayıs 2011

219. Özatay, Parasal İktisat Kuram ve Politika, s.365

220. Yıldırım, Monetary Programming in Turkey After 1990s, s.136

221. A.e.

222. Hasan Ersel Lerzan İskenderoğlu, "Monetary Programming in Turkey", TCMB Tartışma Tebliği, No.9006, 1990, s.2-14

223. Oğuz Yıldırım, “Türkiye'de Parasal Programlama ve Enflasyon Hedeflemesi”, Basılmamış Eser, t.y. ,s.7

224. TCMB, Yillık Rapor 1996

225. TCMB, Yıllık Rapor 1997

226. Olcay Yücel Emir, Almila Karasoy ve Kürşat Kunter, “Monetary Policy Reaction Function in Turkey”, TCMB Tartışma Tebliği, 2000, s.6-9 
227. Erçel, 1998 Yılı Para Politikası Uygulaması: Basın Toplantısı, Ankara, 8 Ocak 1998.

228. Emir, Karasoy ve Kunter, a.g.e., s.9

229. Gazi Erçel, "Disinflation Program for the Year 2000: Implementation of Exchange Rate and Monetary Policy", TCMB, 1999.

230. Erinç Yeldan, "Birinci Yılında 2000-Enflasyonu Düşürme Programının Değerlendirilmesi”, Mülkiye Dergisi, Cilt: XXV, Sayı: 226, Ocak-Şubat 2001, ss.157-174, s.158

231. Erçel, Disinflation Program for the Year 2000: Implementation of Exchange Rate and Monetary Policy, 1999.

232. Emir, Karasoy ve Kunter, a.g.e, s. 9

233. Maurice Obstfeld, "Can We Sterilize? Theory and Evidence", NBER Working Paper, No.833, 1982, s.1

234. Eroğlu, İktisatta Rasyonalite ve Para Politikası, s. 73

235. Fischer, Maintaining Price Stability, s.36

236. Oktar, Enflasyon Hedeflemesi, s.22

237. Jeffrey A. Frankel, Sergio L. Schmukler and Luis Servén, “Global Transmission of Interest Rates:Monetary Independence and Currency Reg1me", Working Paper, No.8828, March 2002, s.1

238. Oktar, Enflasyon Hedeflemesi, s.22

239. Fischer, Maintaining Price Stability, s.36

240. Doğruel ve Doğruel, a.g.e., , s.61

241. A.e.

242. Fischer (2000)'den aktaran a.g.e, s.63

243. Çağlar, a.g.e., s.153

244. Milton Friedman bunu A Monetary History of the United States, 1867 1960, Princeton University Press, s.676'da şöyle dile getirmektedir": The interrelation between monetary and economic change has been highly stable"

245. Çağlar, a.g.e., s. 155

246. A.e., s. 20

247. Parası, Para Politikası, s. 188

248. Oktar, Enflasyon Hedeflemesi, s.23

249. Fischer, Stanley "Maintaining Price Stability," Finance \& Development, Cilt:33, No: 4, Aralık, ss. 34-37, 1996, s.37

250. Peter Montiel and Jonathan Ostry, "Targeting The Real Exchange Rate in Developing Countries", Finance and Development, vol.30, No.1, March 1993, s.38 
251. Oktar, Enflasyon Hedeflemesi, s.7

252. Özatay, Nas1l Oluyor da Oluyor Finansal Krizler-1, 2011

253. Graciela L. Kaminsky, "Varieties of Currencies Crisis “, NBER Working Paper, No.10193, 2003., s.21

254. Fatih Özatay, Finansal Krizler ve Türkiye, Doğan Kitap, 2.Bask1, İstanbul, 2010, s.37.

255. Paul Krugman, "A Model of Balance-of-Payments Crises", Journal of Money, Credit, and Bankıng, Vol.11, No.3, 1979, pp.311-325, s.322

256. Fatih Özatay, Nasıl Oluyor da Oluyor Finansal Krizler-1, Dünya Gazetesi, 24.08.2011

257. A.e.

258. Kaminsky, a.g.e., s.1

259. Çağlar, a.g.e., s. 155

260. Özatay, Finansal Krizler ve Türkiye, s.45-47

261. Çağlar, a.g.e., s.122-123

262. Calvo ve Vegh, a.g.e., s. 2

263. Jaime de Melo and Sumana Dhar," Lessons of Trade Liberalization in Latin America for Economies in Transition", The Worldbank Working Papers, No.1040, November 1992, s.15-17

264. Calvo ve Vegh, a.g.e., s. 2

265. Sebastian Edwards " "Stabilization with Liberalization: An Evaluation of Ten Years of Chile's Experiment with Free-Market Policies, 1973-1983", Economic Development and Cultural Change, Vol. 33, No. 2, Jan. 1985, pp. 223-254, s.223

266. Rudiger Dombusch and Sebastian Edwards, "Exchange Rate Policy And Trade Strategy," in The Chilean Economy: Policy Lessons, Developing Country Debtand Economic Performance, Vol. 2 University of Chicago Press, 1990, s.89

267. Nader Nazmi ,"Exchange Rate-Based Stabilization in Latin America", World Development, Vol. 25, No. 4, pp. 519-535, 1997 s.522 268. A.e.

269. Edwards, Stabilization with Liberalization: An Evaluation of Ten Years of Chile's Experiment with Free-Market Policies, 1973-1983, s.244

270. Raul Laban and Felipe Larrain B., "The Chilean with Capital Mobility", in The Chilean Economy: Policy Lessons, Developing Country Debtand Economic Performance, Vol. 2 University of Chicago Press, 1990, s.124

271. Nazmi, a.g.e., s.522-523 
272. Calvo ve Vegh, a.g.e., s.78

273. Krugman, The Return of Depression Economics, s.38

274. Fatma Doğruel ve A. Suut Doğruel, Türkiye'de Enflasyonun Tarihi, TCMB ve Tarih Vakfı Ortak Yayını, İstanbul, 2005, s.86

275. A.e.

276. Nazmi, a.g.e., s.523.

277. Joseph R. Ramos, Neoconservative Economics in the Southern Cone of Latin America 1973-1983, The Johns Hopkins University Press, 1986'dan aktaran Nader Nazmi, s.523

278. Nazmi, a.g.e., s.524

279. Dombusch and Edwards, a.g.e., s.6

280. Nazmi, a.g.e., s.533.

281. Jose Mari Fanelli, Roberto Frenkel and Guillermo Rozenwurcel, "Growth and Structural Reform in Latin America Where We Stand", Documento CEDES/57, Buenos Aires 1990, s.75-90

282. Calvo ve Vegh, a.g.e., s. 78

283. Roque B. Fernandez, "The Expectations Management Approach to Stabilization in Argentina During 1976-1982", World Development, Volume 13, Issue 8, August 1985, Pages 871-892, s.1

284. Melo ve Dhar, a.g.e., s. 14

285. Doğruel ve Doğruel, Türkiye'de Enflasyonun Tarihi, s.87-89

286. Krugman, The Return of Depression Economics, s.39-40

287. TCMB, Y1llık Rapor 1999

288. A.e.

289. TCMB, Y1llık Rapor 2000, s.71

290. Özatay, Parasal İktisat Kuram ve Politika, s.372.

291. TCMB, Yillık Rapor 2001, s.107

292. Özatay, Parasal İktisat Kuram ve Politika, s.372.

293. Öztürk, a.g.e., s. 1

294. Heean ve diğerleri, 2006.

295. Merkez Bankası toplumaki enflasyonist beklentileri ölçmek için ayda iki kere çeşitli kesimlerle enflasyon beklenti anketi yapmaktadır. Aralık 2011 başı itibari ile Aralık 2013 için öngörülen enflasyon beklentisi toplumda yüzde 7'dir. Yani bireyler tükettikleri mallara gelecek 12 ayda yüzde 7 zaman geleceğini düşünmekteler. Firmalar da yüzde 7 daha maliyetli ürünler üreteceklerini ve zam oranını buna göre ayarlayacaklarını düşünmekteler. 
296. Kara ve Orak, a.g.e., s.8.

297. Carl E. Walsh, Monetary Theory and Policy, Second Ed., MIT Press, 2003, s.541

298. TCMB, enflasyon hedeflemesi, a..e.

299. Bu çalışmalardan bazıları şunlardır: Bernanke and Mishkin (1997); Svensson 1997a, 1997b,1997d, 1999b, 1999c, 1999d; Svensson and Woodford (1999)

300. Bkz. Ammer and Freeman (1995); Bernanke, Laubach, Mishkin, and Posen (1998); Mishkin and Schmidt-Hebbel (2001); Amato and Gerlach (2002); Leiderman and Svensson (1995).

301. Çağlar, a.g.e., s. 154

302. Bernanke and Mishkin, a.g.e., s.2

303. TCMB Enflasyon Raporu 2006-I, s.56

304. TCMB, 2011 Ocak Enflasyon Raporu Basın Toplantıs, s.17

305. Alina Carare, et.al.,"Establishing Initial Conditions in Support of Inflation Targeting", IMF Working Paper, WP/ 02/102, 2002, s.28

306. Fatih Özatay, “Merkez Bankasının Faiz Aracı Etkisizleşiyor mu?”, Radikal Gazetesi, 07.09.2011

307. Merkez bankasının borç verme faiz oranı, geçici likidite sıkışıklığına düşen bir bankanın merkez bankasından aldığı borç karşılığında ödemeyi taahüt ettiği faiz orandır. Borç alma faiz oranı da likidite fazlası olan bankanın bu fazla fonu merkez bankasına mevduat şeklinde vererek karşılığında kendisine verilmesini kabul ettiği faiz oranıdır. Yani borç verme faiz oranı borç alma faiz oranından yüksek çıkmalıdır.

308. Fatih Özatay, "Nasıl Oluyor da Oluyor? Para Politikası (3)”, Dünya Gazetesi, 11 Mayıs 2011

309. Bernanke ve Mishkin, a.g.e, s.1.

310. Carare, et.al, a.g.e., s. 24

311. TCMB, "Sık Sorulan Sorular", (Çevrimiçi), http://www.tcmb.gov.tr/ yeni/iletisimgm/sss.php, Erişim: 06.03.2011.

312. Clarida, R., J. Gali ve M. Gertler. 1999. The Science of Monetary Policy: A New Keynesian Perspective. Journal of Economic Literature Vol. 37, Aralık 1999, s. 1661-1707.

313. Başçı ve Kara, a.g.e., s.3-4

314. Merkez bankası 2002 yılından itibaren kısa vadeli faiz oranları politikasını gelecek dönem enflasyonuna ilişkin unsurları göz önünde bulundurarak belirlemeye başlamıştır (TCMB yıllık rapor 2003, s.76). 
315. Johua Aizenman, Michael Hutchison ve lan Noy, "Inflation Targeting and Real Exchange Rates in Emerging Markets", World Development, 2010, s.5.

316. Frederic S. Mishkin, "Can Inflatıon Targetıng Work In Emergıng Market Countrıes? "NBER Working Paper, No.10646, Temmuz 2004, s.11.

317. A.e,

318. Norman Loayza ve Raimundo Soto, "Inflation Targeting: An Overview", Central Bak of Chile, 2002, s.10

319. Kore ve Tayland Çekirdek enflasyon hedeflerken, Türkiye'nin de içinde bulunduğu geniş bir ülke topluluğu TÜFE genel endeksini hedeflemektedir.

320. Guy Debelle, "Inflation Targeting in Practice," Occasional Papers, No 23, The South East Asian Central Banks Research and Training Centre Kuala Lumpur, Malaysia, 1997, s.5-9

321. Fischer, Maintaining Price Stability, s.35.

322. Karasoy, Saygılı ve Yalçın, a.g.e., s. 16

323. Debelle, a.g.e., s.12-13.

324. Para kurulu sistemi problematik bir rejim olmasına rağmen, ülkedeki enflasyon psikolojisini yok etmenin bazen tek çaresi olabiliyor. Arjantin'de para kuruluna geçilmesinin en büyük nedeni stabilizasyon programları için daha önce denenen zayıf taahüt mekanizmalarının çalışmamasıdır. $\mathrm{Bu}$ yüzden de para kurulu ülkedeki enflasyonu kontrol altına almak için çok güçlü ve disiplinli bir araç lazım olduğunda başvurulacak son adım olabilmektedir (Mishkin, Internatıonal Experiences With Different Monetary Policy Regime, s.11-12

325. "Zaman tutarlı politika" için analitik bir örnek: 1'den T'ye olan zaman peryodunda $\pi=\left(\pi_{1}, \pi_{2}, \pi_{3}, \ldots, \pi_{T}\right)$ para otoritesinin tüm politikalar kümesini göstersin. $x=\left(x_{1}, x_{2}, x_{3}, \ldots, \pi_{T}\right)$ de bu politikalara karşılık ekonomik bireylerin aldığı kararlar (duruş ya da tavır) olsun. Üzerinde anlaşmaya varılan bir sosyal amaç fonksiyonunun;

$$
S\left(x_{1}, x_{2}, x_{3}, \ldots, x_{T}, \pi_{1}, \pi_{2}, \pi_{3}, \ldots, \pi_{T}\right)
$$

Şeklinde ifade edildiği varsayılsın. Ekonomik bireylerin t zaman peryodunda aldıkları kararlar tüm politikarın ve geçmişteki aldıkları kararların bir kümesi olarak aşağıdaki gibi ifade edilir:

$$
x_{t}=X_{t}\left(x_{1}, x_{2}, x_{3}, \ldots, x_{t-1}, \pi_{1}, \pi_{2}, \pi_{3}, \ldots, \pi_{T} \quad t=1, \ldots, T\right.
$$

Böyle bir çerçevede optimal para politikası, eğer varsa, (1) nolu fonksiyonun (2) de ifade edilen kısıtlara göre maksimum yapılmasından ortaya çıkan $\pi$ değeri olacaktır. Eğer her bir t zaman peryodu için (1) fonksiyonun maksimizasyonundan çıkan, $\pi_{t}$, önceki birey karaları olan 
$x_{1}, x_{2}, x_{3}, \ldots, x_{\mathrm{t}-1}$, ve gelecek politika kararları $\left(\pi_{s}, \mathrm{~s}>\mathrm{t}\right)$ benzer seçilmişse buradaki $\pi$, tanım gereği,tutarlı bir politikadır. Zaman tutarsızlığı bahse konu olmamaktadır (Finn E. Kydland ve Edward C. Prescott, "Rules Rather than Discretion: The Inconsistency of Optimal Plans", The Journal of Political Economy, Vol. 85, No. 3 (Jun., 1977), pp. 473-492, s.475-476

326. Kara ve Orak, a.g.e., s.5.

327. Ünsal, a.g.e., s.548.

328. A.g.e, s. 552

329. Frederic Mishkin, "What Should Central Banks Do? “ in Monetary Policy Strategy, MIT Press, 2007, s.37-38.

330. Bu kısım büyük ölçüde TCMB, "Enflasyon Hedeflemesi Rejimi”, 2006, s.5-9. ve IMF, "Does Inflation Targeting Work in Emerging Countries", World Economic Outlook, Chapter 4, s.182-185.'den yararlanarak hazırlanmıştır.

331. Oktar, Enflasyon Hedeflemesi, s.35

332. Alesina ve Summers, a.g.e., s.151.

333. Debelle, a.g.e., s.17-18

334. Fatih Özatay, Parasal İktisat Kuram ve Politika s.399.

335. John Faust and Lars E.O. Svensson, "Transparency and Credibility: Monetary Policy with Unobservable Goals", NBER Workıng Paper Serıes No.6452, February 2000, s.6

336. Alex Cukierman, "Central Bank Independence and Monetary Control", Economic Journal, Cilt. 40, No. 1427, 1994, ss. 1437-1448, s.1441

337. Alex Cukierman, "Central Bank Behavior and Credibility Some Recent Theoretical Developments", Federal Reserve Bank of St. Louis Review, 1986, s.6

338. Alex Cukierman, Central Bank Strategy, Credibility, and Independence: Theory And Evidence, Fourth Edition, Massachussets of Technology, 1998 , s. 255

339. Robert Flodd ve Peterd Isard, "Monetary Policy Strategies" NBER Working Paper Series, No.2770, 1988, s.24-25

340. Oktar, Enflasyon Hedeflemesi, s.14

341. A.e., s. 15

342. Flood ve Isard, a.g.e., s. 24

343. Keith Blackburn and Michael Christensen, "Monetary Policy And Policy Credibility: Theories And Evidence", Journal of Economic Literature, Vol. 27, No. 1, 1989, pp. 1-45, s.28 
344. Kumcu, Krizler Para ve İktisatçılar, s.158-159.

345. Şükrü Cicioğlu, "Fiyat İstikrarının Sağlanmasına Yönelik Alternatif Bir Para Politikası Stratejisi: Enflasyon Hedeflemesi”, TUHIS, Şubat-Mayıs 2006, ss. 35-48 2006, s.41

346. BDDK, Finansal Piyasalar Raporu, Say1.22, Haziran 2011, s.4

347. Fatih Özatay, "Nasıl Oluyor da Oluyor? Para Politikası (1)", Dünya Gazetesi, 2011

348. TCMB, Enflasyon Hedeflemesi Rejimi, 2006, s.26

349. Özatay, Parasal İktisat Kuram ve Politika, s.397

350. Morris Goldstein and Philip Turner, "Banking Crises in Emerging Economies: Origins and Policy Options", BIS Economic Paper, No.46, October 1996, s. 14

351. Graciela L. Kaminsky and Carmen M. Reinhart, "The Twin Crises: The Causes of Banking and Balance-Of-Payments Problems", The American Economic Review, Vol. 89, No. 3 (Jun., 1999), pp. 473-500.

352. Özatay, Nas1l Oluyor da Oluyor Finansal Krizler-1, 2011

353. Masson, Savastano ve Sharma, a.g.e., s.22-25

354. Goldstein ve Turner, a.g.e, s.12

355. Özatay, Nasıl Oluyor da Oluyor? Para Politikası (1), 2011

356. Williamson ve Mahar, a.g.e., s. 88

357. Özatay, Nasıl Oluyor da Oluyor? Para Politikası (1), 2011

358. N. Kamuran Malatyalı, "Enflasyon Hedeflemesi, Ülke Uygulamalar1na Örnekler ve Türkiye'de Uygulanabilirliği”, DPT Çalışma Raporları, No.1, 1998, s.54-55

359. Guillermo Calvo ve Frederic S. Mishkin "The Mirage of Exchange Rate Regimes for Emerging Market Countries," The Journal of Economic Perspectives, Vol. 17, No. 4., 2003, pp. 99-118., s.104.

360. Jeffrey D. Amato ve Stefan Gerlach, "Inflation Targeting in Emerging Market and Transition Economies: Lessons After a Decade," European Economic Review, Cilt: 46, No: 4-5, May1s, ss. 781-90., 2002, s.784.

361. Durmuş Yılmaz, Ekonomik Görünüm, TCMB, Malatya, 7 Eylül 2006, s. 10

362. Kaya, a.g.e., s.195.

363. Ercan Uygur, "Enflasyon, Para ve Mali Bask1: İktisat Politikasında Geri Kalmışlık" İktisat, İşletme ve Finans, Y11:16, Say1:189, 2001, s. $7-23$

364. Tüm mevduatlar içindeki yabancı mevduatların oranı 
365. İhracat ve ithalatın toplam değerinin GSYIH'ya oranı

366. Nadia Saleem, “ Adopting Inflation Targeting in Pakistan: An Empirical Analysis", The Lahore Journal of Economics, No. 15:2, 2010, pp.51-76, s.62

367. Alternatif bir endeks türü olarak da GSYİH deflatörü dikkat çekmektedir. bu endeks hem sık açıklanmadığı hem de içerisindeki mal ve hizmetlerin sürekli bir değişime uğraması nedeniyle uygulanan para politikalarının güvenirliğine ve şeffaflığına potansiyel bir tehlike oluşturacağı düşünülmektedir (Schaechter ve diğ., 2000, Kara ve Orak, ag.e, s.8)

368. Kara ve Orak, a.g.e., s. 8

369. Ferya Kadıŏlu, Nilüfer Özdemir ve Gökhan Yılmaz, "Inflation Targeting in Developing Countiries", TCMB Tartışma Tebliği, 2000, s.16

370. 2011 şubat ayında yeni enflasyon sepetinden 2 madde çıtı, 4 madde ise yeni sepete dahil oldu.Sepetten, tütün ve elbise dikiş ücreti çıkarken, erkek kot mont, uyku seti, ved film kiralama ve özel dersane OKS hazırlık ücreti listeye dahil oldu...Yeni sepete giren madde çeşidi ise 68 oldu. Yeni dönemde 26 madde çeşidi ise liste dışında kaldı. Bu gelişmeler sonucunda daha önce 442 olan madde sayısı 444'e, 736 olan madde çeşidi sayısı ise 778 'e yükseldi.Yeni dönemde geçen yıl 22 bin iş yerinden derlenen fiyatlar da, 24 bin 600 iş yerinden alınmaya başlanacak (Kaynak: TUIK)

371. Goffrey Heenan, Marcel Peter ve Scott Roger, "Implementing Inflation Targeting:Institutional Arrangements, Target Design, and Communications", IMF Working Paper, No.278, 2006, s.18.

372. Kara ve Orak, a.g.e., s.9 ; Andrea Schaechter, Mark Stone ve Mark Zelmer, “Adopting Inflation Targeting: Practical Issues for Emerging Market Countries”, IMF Occasional Paper, No. 202, 2000.

373. Kevin X.D. Huanga and Zheng Liu,'Inflation Targeting: What Inflation Rate to Target", Journal of Monetary Economics, No.52, ss.1435-1462, 2005, s.1427.

374. Marvin Goodfriend, Robert G.King, "The Case for Price Stability", Working Paper, No.8423, 2001, s.1

375. Frederic S. Mishkin, "Inflation Targeting," National Bureau of Economic Research", 2000, s.13.

376. Ercan Kumcu, "9 Ayda Etki Yapmayan Politika Politika Olamaz", Habertürk, 18 Mayıs 201

377. Ben S.Bernanke, Thomas Laubach, Frederic S. Mishkin ve Adam S.Posen, Inflation Targeting: Lessons from the International Experience, Princeton, N. J.: Princeton University Press, 1999, s.31 
378. Mishkin ve Schmidt-Hebbel, a.g.e., s.14

379. TCMB, Y1llık Rapor 2007, 24 Nisan 2008, s.38-39

380. TCMB, Yillık Rapor 2009, 20 Nisan 2010, s.40

381. A.e., s. 41

382. Mishkin, Issues in Inflation Targeting, s.13.

383. Bank of Canada,(Çevrimiçi),http://www.bankofcanada.ca/rates/indicators/ key-variables/inflation-control-target/\#targetrange, Erişim: 27.05.2011.

384. Özatay, Parasal İktisat Kuram ve Politika, s.405-406

385. Fatih Özatay, "Örtük Hedefleme Nasıl Doğdu”, Radikal Gazetesi, 12 Haziran 2006.

386. TCMB, Y1llık Rapor 2005, s.73

387. TCMB, "2002 Yılında Para ve Kur Politikaları ve Muhtemel Gelişmeler", Basin Duyurusu 2 Ocak

388. TCMB, Enflasyon Hedeflemesi Rejimi, s.16-17

389. TCMB, 2002 Yılında Para ve Kur Politikası Muhtemel Gelişmeler

390. 2001 şubat ayında dalgalı kur rejimine geçilmesinin en önemli nedenlerinden bir tanesi de merkez bankasının rezervlerini kaybetmesinin önüne geçmek ve kur riskini piyasaya yüklemek istemesidir.2001 y1lında 25 milyar dolar olan döviz rezervleri iki günde dokuz milyar dolar azalınca döviz rezervlerini daha fazla eritmek istemeyen banka hükümetle ortaklaşa karar alarak, sabit kurdan dalgalı kura geçmiştir.(Süleyman Yaşar, “Kendi Portföyünüz mü Türkiye mi?”, Sabah Gazetesi, 10 Ekim 2011

391. TCMB, A.e

392. TCMB,

393. TCMB, "2011 Yılında Para ve Kur Politikası", (Çevrimiçi), www.tcmb .gov.tr, Erişim:23.11.2011

394. TCMB, 2002 Yılında Para ve Kur Politikaları ve Muhtemel Gelişmeler

395. TCMB, “2005 Yllında Para ve Kur Politikaları”, s.2-3.

396. Özatay, Parasal İktisat Kuram ve Politika, s.406-407

397. Kara ve Orak, a.g.e, s.37-38

398. Özatay, Parasal İktisat Kuram ve Politika, s.410-411

399. Durmuş Yılmaz, 75. Olağan Genel Kurul Toplantısı Açış Konuşması, Ankara, TCMB, 6 Nisan 2007, s.3

400. A.e., s.6

401. Para Politikas1 Kurulu önceden ilan edilen takvime göre toplanacak ve politika kararları kamuoyuyla paylaşılacaktı. Alınan kararların sebepleri de kamuoyu ve hükümetle paylaşılacaktı 
402. Kara ve Orak, a.g.e, s.38.

403. Yılmaz, 75. Olağan Genel Kurul Toplantısı Açış Konuşması, s.3-4

404. TCMB, Yıllık Rapor 2006, s.37

405. Yılmaz, Ekonomik Görünüm, s.4.

406. Özatay, Parasal İktisat Kuram ve Politika, s.415-416

407. 3 Haziran 2008 Tarihli TCMB Mektubu

408. Yapılan çalışmalar faiz politikasının ekonomi üzerindeki etkisini3-6 ay arasında öngörmektedir.

409. TCM Yillık Rapor 1999

410. Kumcu, a.g.e., s.161.

411. Y1lmaz, Ekonomik Görünüm, s.11

412. A.e

413. Aynı dönemde MB'nın altın rezervlerinde de yüzde 374'lük bir artış gerçekleşmiştir

414. A.e., s. 12

415. Yılmaz, 75. Olağan Genel Kurul Toplantısı Açış Konuşması, s.8.

416. TCMB, Bülten, Mart 2006, Say1 1, s.1-2

417. Ünsal, a.g.e., s.556

418. Parasız, Para Politikas1, s.93

419. Edwards, The Relationship Between Exchange Rates and Inflation Targeting Revisited, s.1-47.

420. Masson, Savastano ve Sharma, a.g.e., s.11

421. Svensson, Inflation Targeting as A Monetary Policy Rule, s.13

422. Frederic S. Mishkin, "Inflatıon Targetıng", National Bureau of Economic Research, 2001, s.2-3

423. Frederic S. Mishkin, "International Experiences With Different Monetary Polıcy Regımes", Seminar Paper No. 648, 1998, s.22

424. Enzo Croce ve Mohsin S. Khan"Monetary Regimes and Inflation Targeting," Finance and Development, Cilt. 37, No. 3, September, 2000, s.50.

425. Frederic S. Mishkin ve Miguel A. Savastano "Monetary Policy Strategies for Latin America," Journal of Development Economics, 2001, s.429.

426. Frederic S. Mishkin ve Adam Posen, "Inflation Targeting: Lessons From Four Countires," Federal Reserve Bank of New York Economic Policy Review, Cilt: 3, No.3, 1997, s.7.

427. Oktar, Enflasyon Hedeflemesi, s.59

428. Masson, Savastano ve Sharma, a.g.e., s.20

429. Mishkin, Inflation Targetıng, s.6 
430. Sosyal refah, işsizliğin ve enflasyonun birlikte ele alınması ile, $L_{t}=\frac{1}{2} P_{t}^{2}+\chi \frac{1}{2} U_{t}^{2}$, denkleminin minimum kilınmasına dayanır. Burda P fiyatları, $\chi$ işsizliğe verilen önem ve $U$ da işsizlik haddini göstermektedir (Sylvester Eijffinger ve Eric Schaling, "The Ultimate Determinants of Central Bank Independence", Center Conference 'Positive Political Economy: Theory and Evidence', January 23-24, 1995, Tilburg, The Netherlands, s.7.

431. Svensson, a.g.e., s.15.

432. Oktar, Enflasyon Hedeflemesi, s. 51

433. Mishkin ve Savastona, a.g.e., s.432

434. Mishkin, Inflation Targeting in Emerging-Market Countries, s.4.

435. Karasoy, Saygılı ve Yalçın, a.g.e., s. 15-16

436. Mishkin, Inflation Targeting in Emerging-Market Countries, s.4.

437. Barro ve Gordon, a.g.e

438. Özatay, Parasal İktisat Kuram ve Politika, s.312-313.

439. Stanley Fischer, " Rules Versus Discretion in monetary Policy”, NBER Working Paper Series, No.2518, Şubat 1988, s.17

440. Benjamin Friedman ve Kenneth N. Kuttner, "A Price Target for U.S. Monetary Policy? Lessons From The Experience with Money Growth Targets," Brookings Papers on Economic Activity, Vol. 1996, No.1, 1996, pp. 77-146, s.10

441. Taylor, Discretion Versus Policy Rules in Practice, s.202. Ayrıntılı bilgi için bkz: Kydland, F. and Prescott, E.C., (1977), Rules Rather than Discretion: The Inconsistency of Optimal Plans, Journal of Political Economy, 85:473-92; Barro, R.J. and Gordon, D.B., (1983), Rules, Discretion and Reputation in a Model of Monetary Policy., Journal of Monetary Economics, 12:101-22.; Olivier Jean Blanchard, and Stanley Fischer, Lectures on Macroeconomics, Cambridge, Mass.: MIT Press, 1989.

442. Özatay, Parasal İktisat Kuram ve Politika, s.313.

443. Ben Bernanke ve Frederic S. Mishkin: "Inflation Targeting: A New Framework for Monetary Policy?”, NBER Working Papers, No.5893, January 1997.

444. Taylor, Discretion Versus Policy Rules in Practice, s.202

445. A.e

446. Fatih özataya, Parasal İktisat Kuram ve Politika, s.404

447. A.e., s.394-395

448. Andrew Berg Eduardo Borensztein Paolo Mauro, "An Evaluation of Monetary Regıme Optıons for Latın Amerıca”, Central Bank of Chile Working Papers, 2002, s.18 
449. Rogoff, The Optimal Degree of Commitment to an Intermediate Monetary Target, s. 1186

450. Svensson, Inflation Targeting as A Monetary Policy Rule, s.13

451. Kadıŏlu, Özdemir ve Yılmaz, a.g.e., s.21-22

452. Carlos A. Vegh, "Stopping High Inflation", IMF Staff Papers, Vol.39, No.3, pp.625-695, Eylül 1992, s.631

453. Gelişmiş ülkelerin senyoraj gelirleri GSYİH'nın yüzde 1'inden düşük iken bu oran gelişmiş ülkeler için yüzde 1.4-3.0 arasında değişmektedir.

454. Kadığlu, Özdemir ve Yılmaz, a.g.e., s.22-24

455. Mishkin ve Schmidt-Hebbel, a.g.e.,, s.6

456. A.e.

457. A.e.

458. Mishkin ve Posen, a.g.e., s.29

459. Oktar, Enflasyon Hedeflemesi, s.75-77

460. Peter Nicholl ve David J. Archer, "An Announced Downward Path for Inflation." In Richard O'Brien, Ed., Finance And The International Economy, No. 6, Oxford University Press., December 1992, s.6

461. Policy Targets Aggrement (PTA) adı verilen anlaşma maliye bakanı ile Merkez bankası başkanı arasında 2 Mart 1990'da imzalandı. Aralık 1992 yılında revize edildi. Anlaşma enflasyon için bir hedef değer vermeye ve bunun gerçekleşeceği bir son tarhi içermektedir.( Carl E. Walsh, 1995, s.1181)

462. David J. Archer, "The new Zealand Approach to Rules and Discretion in Monetary Policy”, Journal of Monetary Economics, No.39, pp.3-15, 1997, s.4-5

463. Nicholl ve Archer, a.g.e., s. 120

464. Mishkin ve Posen, a.g.e., s. 34

465. Oktar, Enflasyon Hedeflemesi, s.78-80

466. Carl E. Walsh, "Is New Zealand's Reserve Bank Act of 1989 an Optimal Central Bank Contract?", Journal of Money, Credit and Banking, Vol. 27, No. 4, Part 1 (Nov., 1995), pp. 1179-1191, 1995, s.1182.

467. Andreas M. Fischer and Adrian B.Orr, "Monetary Policy Credibility and Price Uncertainity: The New Zealand Experience of Inflation Targeting", OECD Economic Stıdies,No.22, pp.155-179, 1994, s.158-159

468. Frederic S. Mishkin, "Issues in Inflation Targeting," National Bureau of Economic Research", June 2000, s.12

469. Malatyal1, a.g.e, s.28 
470. Oktar, Enflasyon Hedeflemesi, s.79

471. Mishkin ve Posen, a.g.e., s. 47

472. 1983-1986 arası dönemde bütçe açığının GSYİH'ya oranı ortalama yüzde -5 kadardır.

473. John Ammer ve Richard T. Freeman, “ Inflation Targetting in the 1990s: The Experiences of New Zealand, Canada, and The United Kingdom", Board of Governors of The Federal Reserve System International Finance Discussion Papers, No.473, June 1994, s.14

474. A.g.e., s. $28-30$

475. Murat Kaygusuz "Enflasyon Hedeflemesi ve Türkiye'de Uygulanabilirliği", Econturk Online, 2004.”, s.13, Çevrimiçi: http://www.econturk.org/ Turkiye2004.html, Erişim: 20 .09.2011

476. A.e.

477. David Dodge, "Inflation Targeting in Canada: Experience and Lessons", Economics and Finance, No.13, 2002, ss.113-124, s.119

478. Michael Bruno ve William Easterly, "Inflation Crises and Long-Run Growth", Polıcy Research Working Paper 1517, 1995, s.3.

479. Kadıoğlu, Özdemir ve Yılmaz, a.g.e, s.26-32

480. Kaygusuz, Enflasyon Hedeflemesi ve Türkiye 'de Uygulanabilirliği, s.16

481. Dionísio Dias Carneiro, "Inflation Targeting in Brazil: What Difference does a Year Make?", Texto Para Discussão, No.429, Ağustos 2000, s.4-5

482. Ünsal, a.g.e, s.556.

483. $P Y$ gerçekleşen GSYİH'yı Y* da hedeflenen GSYİH'yı göstermektedir.

484. Rogoff, The Optimal Degree of Commitment to an Intermediate Monetary Target, s.1181-1182.

485. Svensson, Inflation Targeting as A Monetary Policy Rule, s. 26

486. Oktar, Enflasyon Hedeflemesi, s.7

487. $i=r+P$ olduğunu hatırlayalım (P: enflasyon, İ: nominal faiz, r:reel faiz)

488. Oktar, a.g.e., s.26

489. Fischer, Maintaining Price Stability, s.37

490. Rogoff, The Optimal Degree of Commitment to an Intermediate Monetary Target, s. 1186

491. Erdem Başçı, "Central Bank of The Republic of Turkey”, sunumlar, IMF Toplantıları, Washington,April 2011, s,.9-10

492. Özatay, Nasıl Oluyor da Oluyor? Para Politikası (2)

493. Başçı ve Kara, a.g.e.,, s.3-4

494. Merkez bankası Faiz koridoru olarak gecelik borç verme ve borçlanma 
faizleri arasındaki farkı genişleterek faiz koridorunu aktif bir para politikası aracı haline getirip, faizlerdeki oynaklığını minimize etmeye ve esnek bir faiz politikası izlemeye çalışmaktadır (Başçı, a.g.e, s.5)

495. TCMB, Finansal İstikrar Raporu, Mayıs 2011, s.22-23

496. Kumcu, 9 Ayda Etki Yapmayan Politika Politika Olamaz

497. Aslında Türkiye'deki cari açık sorunu yapısaldır. Tasarruflarla yatırımlar arasındaki farktan kaynaklanmaktadır. Merkez bankası politikaları ile bir noktaya kadar azaltılabilir. Bireylerin tüketim eğilimleri kısa vadede aşa$\breve{g} 1$ çekilemeyeceğine göre, yurtiçi tasarrufların arttırılması gerekmektedir. Bunun için yapılması gereken de her yıl işgücüne katılan bir milyonun üzerindeki geniş kesimlere iş imkânı sağlanmasıdır. Bu işsiz kesim önce istikrarlı bir gelire sahip olacak ki tasarruf yapabilsin.

498. TCMB, Enflasyon Raporu, Aralık 2007-IV, s. 48

499. TCMB, Finansal İstikrar Raporu, Aralık 2010, Sayı 11, s.40

500. A.e, s.6

501. Deniz Gökçe, Merkez Bankamız İyi Yönetiliyor, Akşam Gazetesi, 30 Kasim 2011.

502. Başçı ve Kara, a.g.e., s.5-8

503. TCMB, Enflasyon Raporu, Ocak 2011, s.16

504. Başçı ve Kara, a.g.e., s. 15

505. Özatay, Nasıl Oluyor da Oluyor? Para Politikası (4)

506. 2011 yılı Eylül ayı itibari ile Türk bankacılık sektöründe kullandırılan kredilerin yıllık artış oranı \% 20-25 aralığına yükselmiştir. Bu kredilerin kaynağı olan mevduatlar ise yılda yılda \% 10-11 aralığında artış göstermektedir. Bu çarpıklık, dış tasarrufları kullandırmaya ve sonucunda cari açığın ortaya çıkmasına neden oluyor.

507. C.Lim, F. Columba, A. Costa, P. Kongsamut, A. Otani, M. Saiyid, T. Wezel, ve X. Wu, "Macroprudential Policy: What Instruments and How to Use Them? Lessons from Country Experiences", IMF Working Paper, No.238, 2011, 